\title{
Information and communication technology-based cardiac rehabilitation homecare programs
}

This article was published in the following Dove Press journal:

Smart Homecare Technology and TeleHealth

2 April 2015

Number of times this article has been viewed

\section{Marlien Varnfield \\ Mohanraj Karunanithi \\ Australian eHealth Research Centre, Commonwealth Scientific and Industrial Research Organization, Royal Brisbane and Women's Hospital, Brisbane, Australia}

\begin{abstract}
Cardiac rehabilitation (CR) has, for many years, been a highly recommended approach to secondary prevention for patients recovering after a heart attack or heart surgery. These programs are traditionally delivered from a hospital outpatient center. Despite demonstrated benefits and guideline recommendations, CR utilization has been poor, particularly in women, older patients, and ethnic minority groups. To overcome some of the barriers to the traditional delivery of CR, different delivery platforms and approaches have been developed in recent years. In general, Telehealth solutions which have been used to address the delivery of CR services remotely include: 1) patient-provider contact delivered by telephone systems; 2) the Internet, with the majority of patient-provider contact for risk factor management taking place online; and 3) interventions using Smartphones as tools to deliver CR through (independently or in combination with) short message service messaging, journaling applications, connected measurement devices, and remote coaching. These solutions have been shown to overcome some of the barriers in CR participation and show potential as alternative or complementary options for individuals that find traditional center-based CR programs difficult to commit to. The major benefits of remote platforms for CR delivery are the ability to deliver these interventions without ongoing face-to-face contact, which provides an opportunity to reach large numbers of people, and the convenience of selecting the timing of cardiovascular disease management sessions. Furthermore, technologies have the potential to deliver long-term follow-up, which programs delivered by health professionals cannot afford to do due to staff shortages and budget restrictions. However, change in the existing CR services is not without challenges. There is a need to identify development issues that can hamper the implementation of the interventions outside controlled trial settings systems, which may require new computing infrastructures, specific clinical responsibilities, time for training, and development and openness to new ways of doing things.
\end{abstract}

Keywords: cardiovascular disease, Telehealth, telephone, Internet, mobile phones

\section{Background}

In developed countries, cardiovascular disease (CVD) remains the leading cause of death and disability, despite the gradual decline in disease rates experienced over the last few decades. In 2000, 48.6\% of deaths in developed countries were attributed to CVD, which is not expected to change by 2020 , with $46.4 \%$ of all deaths in developed countries still expected to be attributable to CVD. ${ }^{1}$

The way in which CVD is treated has huge implications for patients, health professionals, and policymakers. Once a person has a cardiac event such as a heart attack, the prevention of further heart attacks, stroke, or death is crucial. Secondary prevention through cardiac rehabilitation (CR) is a key component of the ongoing
Correspondence: Marlien Varnfield Australian eHealth Research Centre, Commonwealth Scientific and Industrial Research Organization, Level 5, UQ Health Sciences Building, 901/16 Royal Brisbane and Women's Hospital, Herston, Queensland, 4029, Brisbane, Australia Tel +6I 732533603

Fax +61732533690

Email marlien.varnfield@csiro.au 
care of these patients, immediately following discharge from hospitals. ${ }^{2}$ Today, CR is widely accepted as a proven program that provides health benefits and long-term management of cardiac conditions. CR programs offer a cost-effective, multidisciplinary, and comprehensive approach to address risk factors and to restore individuals to their optimal physiological, psychosocial, nutritional, and functional status, thereby reducing morbidity and mortality. ${ }^{3-5}$

Since the introduction of CR programs, the traditional mode of delivery has been mainly from hospital- or community center-based settings. Traditional hospital- or community center-based CR is considered to be a long-term program that consists of multiple phases. ${ }^{6,7}$ While delivery of CR in the United Kingdom (UK) and United States (US) consists of four phases, in Australia, the delivery is generally performed in three phases, ${ }^{8}$ as shown in Figure 1. Inpatient rehabilitation (phase 1) is an early intervention during the stay in hospital and is mostly undertaken on an individual basis, whereas ambulatory CR programs after discharge from hospital, phase 2, are usually conducted with groups of patients and are generally based upon supervised ambulatory programs conducted in a suitable outpatient setting of the treating hospital. ${ }^{8}$ The more immediate objectives of phase 2 are to achieve clinical stability, limit the physiological and psychological effects of cardiac illness, improve the functional status, and maintain independence with an emphasis on quality of life (QoL). The program is individually designed and the sessions typically occur once or twice a week for 6-8 weeks. Formal outpatient CR programs vary widely in content, but almost all include an element of structured group exercise. Education is usually also delivered. The longer- term objectives, outlined in phase 3 of the CR program, are to reduce the risk of future coronary events, slow the progression of the underlying atherosclerotic process and clinical deterioration, and ultimately reduce morbidity and mortality. ${ }^{8}$ Phase 3 is thus an ongoing maintenance phase beyond inpatient and outpatient rehabilitation, which involves sustained activities and behavior to reduce CVD risk factors through self-management.

Despite the clear benefits of CR programs, studies continue to demonstrate that the participation rates of eligible patients in CR programs remain alarmingly low. ${ }^{9,10}$ In Australia, only $19 \%-36 \%$ of patients completed a CR program in New South Wales, ${ }^{11-13}<20 \%$ in Queensland, ${ }^{14}$ and remote Indigenous patients are even less likely to participate in CR programs. ${ }^{15}$ The low CR participation rate in Australia is reflective of other developed countries. Large UK studies showed low rates of participation $(24 \%-40 \%)$ by eligible patients. ${ }^{6,16}$ Furthermore, similar low rates of CR participation have been demonstrated in the US (19\%-64\%), ${ }^{9,17-19}$ Canada $(45 \%-49 \%),{ }^{20,21}$ and the Netherlands $(11 \%) .{ }^{22}$

Current delivery models of CR, specifically during phase 2, are marred by barriers to participation related to referral, patient, and systemic factors. Barriers include limited referrals by physicians to $\mathrm{CR},{ }^{23,24}$ because of skepticism regarding the benefits of $\mathrm{CR}$ programs, doubts about the likelihood of lifestyle changes resulting in the desired outcomes, ${ }^{25,26}$ and logistic reasons such as site locations and a lack of standardized referral forms. ${ }^{27}$ Systemic factors relate to a lack of availability and often to geographical inaccessibility ${ }^{28,29}$ and, furthermore, to limited transportation and a lack of parking, ${ }^{29,30}$ course content and inconvenient program

\begin{tabular}{|c|c|c|c|c|}
\hline Primary prevention & \multicolumn{4}{|c|}{ Secondary prevention } \\
\hline $\begin{array}{l}\begin{array}{l}\text { Healthy } \\
\text { lifestyle }\end{array} \\
\begin{array}{l}\text { Reduces risk of } \\
\text { cardiac events }\end{array}\end{array}$ & $\begin{array}{c}\begin{array}{c}\text { Cardiac } \\
\text { event }\end{array} \\
\begin{array}{c}\text { Treatment } \\
\text { in hospital }\end{array}\end{array}$ & $\begin{array}{l}\text { Inpatient cardiac } \\
\text { rehabilitation }\end{array}$ & $\begin{array}{l}\text { Outpatient cardiac } \\
\text { rehabilitation }\end{array}$ & $\begin{array}{l}\text { Maintenance } \\
\text { phase }\end{array}$ \\
\hline & & $\begin{array}{l}\text { Usually about } 1 \text { week } \\
\text { Aims to provide: } \\
\text { - Basic information } \\
\text { and reassurance } \\
\text { - Supportive } \\
\text { counseling } \\
\text { - Guidelines for } \\
\text { mobilization } \\
\text { - Appropriate } \\
\text { discharge planning } \\
\text { - Referral to } \\
\text { outpatient cardiac } \\
\text { rehabilitation }\end{array}$ & $\begin{array}{l}\text { Usually } 6-8 \text { weeks } \\
\text { program aimed at } \\
\text { regaining functional ability } \\
\text { Aims to provide: } \\
\text { - Assessment review and } \\
\text { follow-up } \\
\text { - Physical activity and } \\
\text { exercise training } \\
\text { - Behavior modification } \\
\text { strategies and risk factor } \\
\text { management } \\
\text { - Nutritional counseling } \\
\text { - Psychological counseling } \\
\text { and psychosocial } \\
\text { management }\end{array}$ & $\begin{array}{l}\text { Sustained activities and } \\
\text { behavior } \\
\text { Aims to result in: } \\
\text { - Reduction in risk of } \\
\text { future coronary events } \\
\text { - Delay in progression of } \\
\text { underlying } \\
\text { atherosclerotic process } \\
\text { and clinical } \\
\text { deterioration } \\
\text { - Reduction in morbidity } \\
\text { and mortality }\end{array}$ \\
\hline
\end{tabular}

Figure I The three phases in the traditional secondary prevention of cardiovascular disease in the Australian cardiac rehabilitation service delivery model. 
scheduling, ${ }^{31}$ and financial costs. ${ }^{29}$ Patient barriers include limited participation by females, ${ }^{9,32}$ older age, ${ }^{32}$ a dislike of group-based classes ${ }^{29}$ a lack of personalization of exercise programs, ${ }^{33}$ competing demands of returning to work, ${ }^{31,34}$ family commitments (particularly among females), ${ }^{17,19}$ and a lack of motivation. ${ }^{24}$ Further patient predictors of poor participation in $\mathrm{CR}$ are racial/ethnic minority groups,${ }^{15}$ low socioeconomic status and educational attainment, ${ }^{17}$ low self-efficacy and literacy, and a lack of perceived need for CR. ${ }^{29}$

Attempts to improve access to $\mathrm{CR}$ have led to the design and development of various alternative delivery models of $\mathrm{CR}$, and many have focused on extending CR delivery from traditional center- and hospital-based CR to the patient's home and community. ${ }^{35}$ Over the last decade, these delivery models have increasingly focused on utilizing the advances made in information and communication technologies (ICT). In this paper, we present a review of studies that feature a variety of ICT intervention platforms for the delivery of alternative models of CR. We summarize the research findings and finally discuss the future perspectives of ICT-based CR programs.

\section{Methods}

Published literature that addressed the use of ICT for CR programs at home was identified through a careful search of PubMed, Web of Science, and the Cochrane Library, and other sources of literature were gathered from references included in reviews. No beginning time limit was employed for the search, as studies involving ICT technology in CR were expected to be relatively current and the authors intended to portray the progression of these technologies since their introduction in home-based CR in the late 1990s. Only patients with coronary artery disease were considered for this review. Included studies described patients as having either an acute myocardial infarction (MI), a diagnosis of acute coronary syndrome, or they had undergone a revascularization procedure.

The keywords "cardiac rehabilitation", "secondary prevention", "heart disease", and "cardiovascular disease", were combined with "home-based", "homecare", "Telehealth", "technology", "information and communication technologies", "telephone", "Internet", "mobile phone", and "Smartphone". As this is not a systematic review, the authors included selected exemplary studies that involved technologies such as the telephone, Internet, and/or mobile technology interventions to support home-based CR or secondary prevention programs. Figure 2 shows the search

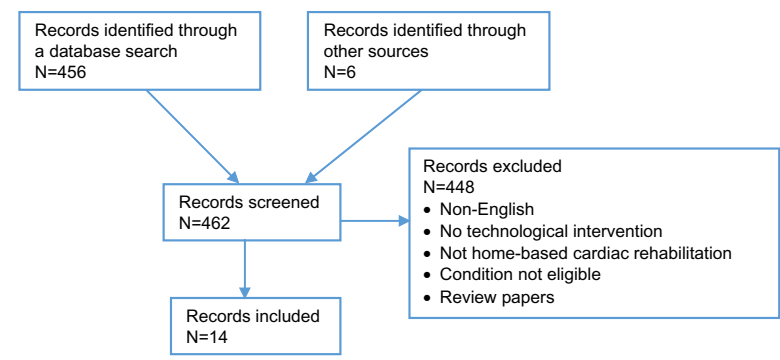

Figure 2 Flow diagram of the literature search and the selection of studies.

results from keywords database searches and other sources, such as references from previous reviews. The results were then screened and excluded, as shown in Figure 2, to specifically include studies in the English language relating to the technology-based homecare delivery of CR.

\section{Application of technology in the delivery of cardiac rehabilitation homecare programs}

Since the 1960s, researchers have been preoccupied with improving CR program delivery into patients' homes through remote monitoring, but these have been limited to the exercise component and not to a comprehensive approach to CR. Recent advances in ICT, however, have shown potential to overcome this limitation by providing the capacity for health ambulatory monitoring and enabling remote coordinated care by the health service provider. The extent of advanced monitoring not only includes electronic weight scales, blood pressure (BP) meters, and thermometers, but also advanced devices such as accelerometers for activity monitoring and sleep-monitoring devices, with many of these becoming wireless and more ambulatory. In addition, the explosive growth of the Internet, personal computers and other digital devices, smart mobile phones, and associated technologies continues unabated. An important component of this growth has been a decrease in the cost to adopt these technologies to one's lifestyle. Hardware and computer processing power, network bandwidth, Internet access, and software costs have all decreased as new technologies become commodities. With these rapid advances made in ICT, opportunities exist to augment homecare, including the provision of remote comprehensive CR programs.

In general, technologies used to address the delivery of remote CR services progressively include: 1) multifactorial Telehealth delivery, with the majority of patient-provider contact delivered by telephone systems; 2) Internet-based delivery of $\mathrm{CR}$ with the majority of patient-provider 
contact online; and 3) interventions using Smartphones as tools to deliver CR through employing, independently or in combination, short message services (SMS) messaging, journaling applications, connected measurement devices, and remote coaching. This paper will review studies that describe interventions in all three categories mentioned earlier, outlined in Table 1. While these studies vary in terms of the intervention used, there was one common objective, which was to improve the uptake and completion of CR programs, while not compromising the quality of care. Figure 3 presents examples of user interfaces used in home-based CR delivery through the 1) Internet and 2) mobile phone applications and the Internet.

\section{Cardiac rehabilitation with telephone support}

The early form of communication technology, being the "traditional" landline telephone, has been used to deliver home-based CR services live by nurse/caregiver visits that were supported by telephone calls and computer-generated mailings; ${ }^{36-38}$ more recently, self-monitoring handbooks and $\operatorname{logs},{ }^{34,39-41}$ and also telephonically transmitted electrocardiogram $(\mathrm{ECG})^{42,43}$ have been utilized to augment such services. "Tele-rehabilitation" began in the mid-1990s, and since then, initiatives in "tele-rehabilitation" programs have been steadily growing.

In 1996, DeBusk ${ }^{36}$ pioneered the delivery of home-based CR using telephone calls and computer-generated progress reports to remotely support patients to manage their CVD risk (MULTIFIT system). DeBusk compared patients with postacute MI undergoing the MULTIFIT home-based CR program (nurse-initiated and supported exercise training, smoking cessation, dietary, and lipid-lowering drug therapy counseling) to those with usual medical care, over 1 year. The MULTIFIT program showed greater improvement than the usual care group in exercise capacity at 6 months, and smoking cessation rates, total cholesterol, and low-density lipoprotein (LDL) cholesterol reductions at 12 months. Subsequent studies that used similar models as the MULTIFIT telephone-supported home-based CR confirmed the improvement in exercise capacity and lipid profiles, but further demonstrated increased social support, health-related quality of life (HRQoL), reduced nurse intervention time, and a twofold capacity to manage CR patients. ${ }^{37,39}$

Another intervention called Coaching patients On Achieving Cardiovascular Health $(\mathrm{COACH})^{38,44}$ employed a comparable home-based model to assist patients with managing coronary risk factors through the management of their medications with their physicians, so as to reach the target levels for their particular risk factors. $\mathrm{COACH}$ incorporated computer-generated mailings and coaching sessions delivered by telephone over a 6 -month period. While this was provided as somewhat optional to $\mathrm{CR}$, where lifestyle behavioral changes were addressed, it did not center on improving physical activity. Through a randomized controlled trial (RCT), COACH showed a significant reduction in total cholesterol and improvements in LDL cholesterol, body mass index (BMI), dietary intake of saturated fat, and general wellbeing, ${ }^{38}$ but despite a greater proportion of COACH program participants reporting taking up regular walking compared to the usual care group, the trial was not effective in improving their physical activity, which is questionable as an outcome of a CR program.

A noteworthy RCT by Dalal et al, ${ }^{34}$ the Cornwall Heart Attack Rehabilitation Management Study (CHARMS), which introduced a self-help manual ("Heart Manual") to a 6-week exercise, stress management, and education with telephonesupported home-based CR, observed changes in anxiety and depression in CR participants following CR at a 9-month follow-up. In this study, 104 patients were randomized to an 8-week hospital-based CR program or a home-based program, and another 126 were given the option to choose either of these CR programs. The home-based program was supported by a CR nurse who made a home visit on the first week after discharge, followed up by typically 4 telephone calls over 6 weeks. The outcomes showed similar improvements on depression or anxiety scores, HRQoL, and total cholesterol levels between the groups, concluding that home-based CR is a viable alternative to a hospital-based program.

In another approach, scripted telephone health coaching sessions $(10 \times 30$ minutes $)$, supported by a handbook and educational resources (ProActive Heart program), were introduced to modify coronary heart disease risk factors. ${ }^{40,45}$ Results of the ProActive program not only demonstrated compliance to recommended levels of physical activity, BMI, vegetable intake, and alcohol consumption, but they also found significant improvements in HRQoL (mental component), social functioning, and role-emotional subscales, ${ }^{40}$ as well as reductions in anxiety. ${ }^{45}$ Although the ProActive program was associated with higher costs compared to usual care, ${ }^{46}$ it was unrelated to the intervention or cardiac-related hospitalization.

Remote physiological monitoring to home-based CR patients became feasible with the introduction of ECG transmission via fixed-line telephone communication. 
Table I Summary of the studies included in this review

\begin{tabular}{|c|c|c|c|}
\hline Study & $\begin{array}{l}\text { Type of trial, } \mathbf{N} \text {, } \\
\text { cardiac event/s }\end{array}$ & Intervention & $\begin{array}{l}\text { Improved primary and/or secondary outcomes } \\
\text { through ICT intervention }\end{array}$ \\
\hline \multicolumn{4}{|c|}{ Multifactorial Telehealth delivery of home-based CR, with the majority of patient-provider contact delivered by telephone } \\
\hline $\begin{array}{l}\text { DeBusk }^{36} \\
(\text { MULTIFIT) }\end{array}$ & RCT, 585, post-MI & $\begin{array}{l}\text { Nurse-initiated phone contacts } \\
\text { Computer-generated progress reports } \\
\text { mailed to patients }\end{array}$ & $\begin{array}{l}\text { At the end of } 12 \text { months, the intervention group } \\
\text { showed significantly greater: smoking cessation } \\
\text { rates; total cholesterol and LDL cholesterol } \\
\text { reductions; functional capacity. }\end{array}$ \\
\hline Kodis et a $\left.\right|^{37}$ & $\begin{array}{l}\text { Retrospective review, } \\
1,042 \text { post-CABG }\end{array}$ & $\begin{array}{l}\text { Prescription and detailed guidelines for } \\
\text { home-based exercise }\end{array}$ & $\begin{array}{l}\text { Substantial improvements at } 6 \text { months in: } \mathrm{VO}_{2} \text {; peak } \\
\text { workload and metabolic equivalents; } \mathrm{HDL} \text { cholesterol. }\end{array}$ \\
\hline
\end{tabular}

$\begin{array}{ll}\text { Vale et a }{ }^{38} & \text { RCT, 792, CABG, } \\ (\text { COACH }) & \text { PCI, AMI, UA }\end{array}$

Arthur et al ${ }^{39}$ RCT, 242 post-CABG two to three times over 6 months Patient contacted by telephone within 2 weeks after randomization

Three telephone coaching sessions at 6-week intervals for 6 months

Patients invited to contact coach if required

Progress reports mailed to participants

A total of 6 months of monitored,

home-based exercise training

Telephoned every 2 weeks

Exercise logs monitored monthly

\begin{tabular}{|c|c|c|}
\hline $\begin{array}{l}\text { Dalal et a }{ }^{34} \\
\text { (CHARMS) }^{\text {CHAR }}\end{array}$ & $\begin{array}{l}\text { RCT and preference } \\
\text { arms, } 230, \mathrm{MI}\end{array}$ & $\begin{array}{l}\text { Nurse support typically provided by four } \\
\text { calls over } 6 \text { weeks } \\
\text { Self-help package (the "Heart" manual) }\end{array}$ \\
\hline Hawkes et $\mathrm{al}^{40}$ & $\mathrm{RCT}, 430, \mathrm{MI}$ & A total of $10 \times 30$-minute scripted telephone \\
\hline O'Neil et a ${ }^{45}$ & & health coaching sessions over 6 months \\
\hline (ProActive & & Handbook for patients and educational \\
\hline Heart) & & resource to use during health sessions \\
\hline
\end{tabular}

resource to use during health sessions

Telehealth delivery of home-based CR, with the patient-provider contact delivere

Ades et al ${ }^{42} \quad$ Controlled study,

I33, CABG, MI, PCI

For 3 months, participants exercised three times

per week with a stationary cycle ergometer

with direct communication to the nurse

Simultaneous conference calls with

other CR patients

Körtke et $\mathrm{al}^{43}$

Open clinical study,

170, CABG, PCI

A 3-month ambulant $C R$

Cardiovascular function recorded by a mobile telemedicine unit (ECG and heart rate monitor) and transmitted telephonically

Delivery of home-based CR with the majority of patient-provider contact fo Lear et al ${ }^{47} \quad \mathrm{RCT}, 78, \mathrm{ACS}$ or PCl A 4-month Internet-based program to mimic (vCRP) a standard hospital-based CR ( $v C R P$ )

Recordable heart rate monitor

Data capture for test results, education sessions, progress notes, monthly ask-an-expert group chat sessions, and private online chat sessions

Clark et $\mathrm{a}^{48}$ (eOCR)

Pilot study, 16 health professionals and 24 patients, post-MI or angioplasty

Internet-based self-management Website system Cardiac case manager delivers education, tracks patient progress, and contacts patients and/or their caregivers via Web-based email and discussion boards or by telephone
Intervention group showed: significant improvement in total cholesterol; substantial improvements in coronary risk factors and in patient HRQoL.

Significant improvement in peak oxygen

in both groups at 6 weeks.

Home group greater total social support at 3 months and 6 months, and greater improvement in HRQoL (physical) at 6 months.

At 9 months, similar results to hospital-based $\mathrm{CR}$ in: depression and anxiety score; HRQoL and; total cholesterol levels.

Significant improvement in health status in both groups, difference between groups not significant. Intervention showed a significant reduction in anxiety.

ed by telephone augmented by ECG monitoring

The home-based group increased peak aerobic capacity to a similar degree to that of on-site CR patients.

Similar HRQoL outcomes.

The intervention showed significant improvement in maximal physical performance, physical and psychological HRQoL, lower cost.

The vCRP group showed significantly higher exercise
The modification via the Internet capacity and dietary quality, with reductions in cholesterol levels.

No differences in lipids, blood pressure, and physical activity were noted between the two study groups.

The Website increased the reach of CR program within regions.

Profiled the potential users of this type of health care (ie, active Internet users).

Online discussion rooms and workbooks were not used.

Interventions using Smartphones as tools to deliver CR remotely through SMS messaging and/or journaling applications, connected measurement devices, and remote coaching

Lounsbury et al ${ }^{49} \quad$ Retrospective analysis, Five to seven SMS messages/week consisting 237, patients enrolled of heart-healthy tips, requests for weight, in $C R$ minutes of exercise, blood pressure, Intervention participants attended significantly more $C R$ sessions and were significantly more likely to complete $C R$ than patients not participating in texting. 
Table I (Continued)

\begin{tabular}{|c|c|c|c|}
\hline Study & $\begin{array}{l}\text { Type of trial, } \mathbf{N} \text {, } \\
\text { cardiac event/s }\end{array}$ & Intervention & $\begin{array}{l}\text { Improved primary and/or secondary outcomes } \\
\text { through ICT intervention }\end{array}$ \\
\hline $\begin{array}{l}\text { Dale et } \text { al }^{50} \\
\text { (Text4Heart) }\end{array}$ & $\begin{array}{l}\text { RCT protocol, } \\
\text { I } 20 \text { (estimate), } \\
\mathrm{MI} \text {, angina, or } \mathrm{PCl}\end{array}$ & $\begin{array}{l}\text { mHealth intervention group receive the core } \\
\text { components of CR delivered via text messages } \\
\text { (SMS) from a library of } 503 \text { messages } \\
\text { and a supporting Website over the course } \\
\text { of } 24 \text { weeks ( } 5-7 \text { messages per week) }\end{array}$ & $\begin{array}{l}\text { Adherence to healthy behaviors at } 6 \text { months, overall } \\
\text { CVD risk, body composition, illness perceptions, } \\
\text { self-efficacy, anxiety/depression, and medication } \\
\text { adherence. }\end{array}$ \\
\hline $\begin{array}{l}\text { Varnfield et } a^{51} \\
\text { (CAP) }\end{array}$ & RCT, I20, MI & $\begin{array}{l}\text { Smartphone application with accelerometer } \\
\text { and health diary, visual feedback, text message } \\
\text { reminders, educational videos, and Web portal; } \\
\text { goal setting and education provided } \\
\text { through weekly telephonic mentoring sessions }\end{array}$ & $\begin{array}{l}\text { Significant higher uptake, adherence, and completion } \\
\text { rates. } \\
\text { Significant improvements on the 6-Minute Walk Test } \\
\text { for both groups from baseline to } 6 \text { weeks. Slight weight } \\
\text { reduction and significant improvements in emotional } \\
\text { state and HRQoL. }\end{array}$ \\
\hline
\end{tabular}

Abbreviations: CR, cardiac rehabilitation; N, number; ICT, information and communication technology; RCT, randomized controlled trial; MI, myocardial infarction; LDL, low-density lipoprotein; $\mathrm{CABG}$, coronary artery bypass surgery; $\mathrm{VO}_{2}$, peak oxygen uptake; HDL, high-density lipoprotein; HRQoL, health-related quality of life; COACH, Coaching patients On Achieving Cardiovascular Health; PCI, percutaneous coronary intervention; AMI, acute myocardial infarction; UA, unstable angina; CHARMS, Cornwall Heart Attack Rehabilitation Management Study; ECG, electrocardiogram; vCRP, virtual cardiac rehabilitation program; vCRP, virtual cardiac rehabilitation program; ACS, acute coronary syndrome; eOCR, electronic outpatient cardiac rehabilitation; SMS, short message system; mHealth, mobile health; CVD, cardiovascular disease; CAP, Care Assessment Platform; CAP-CR, Care Assessment Platform cardiac rehabilitation.

This provided the capacity to monitor home-based exercise programs with ECG recordings sent to care centers for support. Studies were able to demonstrate similar significant improvements in exercise capacity in home-based CR as that of the center-based CR programs. ${ }^{42,43}$
A recent systematic review and meta-analysis, ${ }^{52}$ however, showed that telephone-supported CR interventions for coronary heart disease patients was limited to reducing certain risk factors such as anxiety and depression, while improving systolic BP and the likelihood of smoking cessation.
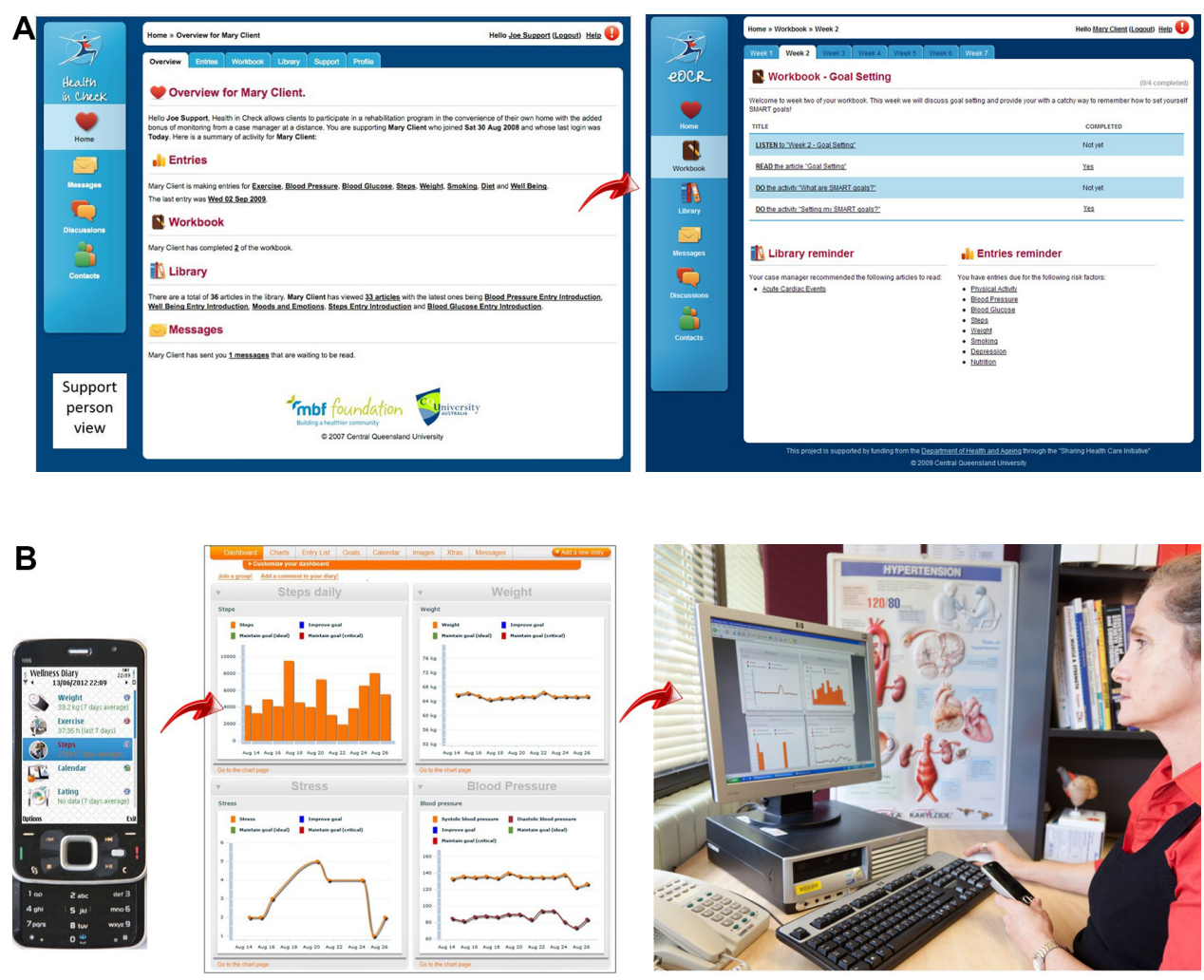

Figure 3 Examples of user interfaces for delivering cardiac rehabilitation through the Internet $(\mathbf{A})$ and a journaling application on a mobile phone combined with portal (B). Figure 3A courtesy of Professors Kerry Mummery and Robyn Clark.

Abbreviation: eOCR, electronic outpatient cardiac rehabilitation. 
Furthermore, telephone-supported CR interventions also have their drawbacks, as possible labor-intensive conversations are expensive; this is supported by less conclusive cost-effectiveness reports of such programs than by reports that are focused on clinical effectiveness. ${ }^{53}$

\section{Cardiac rehabilitation delivery via the Internet and mobile technologies}

The Internet has been used as tool for a range of health interventions, including delivering CR programs. Munro et $\mathrm{al}^{54}$ reviewed the evidence for patient-focused Internet-based approaches to $\mathrm{CR}$. In total, nine studies involving 830 patients with heart disease that compared Internet-based CR to usual care were identified in their study. Outcome data were pooled under four subheadings: compliance; physical activity outcomes; clinical outcomes; and psychosocial outcomes. Although uptake rates with the Internet interventions were mostly high (ranging from 36\%-97\%), adherence was low. Physical activity measures were found to generally improve, as were clinical outcomes. Changes in psychosocial measures such as QoL, anxiety and depression, self-efficacy, and functional emotion were positive in most of these the studies included in the review. None of the interventions noted a negative effect on outcomes.

Two more recent Internet-based CR studies were not included in Munro et al's review. ${ }^{54}$ One of the studies was a virtual CR program (vCRP) ${ }^{47}$, delivered through the Internet, that mimicked standard hospital-based CR delivery. It included a recordable heart rate monitor that connected with the vCRP Website; data capture for exercise stress test and blood test results; education sessions; progress notes; monthly ask-an-expert group chat sessions; and private online chat sessions with clinicians. The vCRP group showed significantly higher exercise capacity and dietary quality. Although there were no differences observed in lipids and blood pressure, this was ascribed to the baseline values being already in the healthy range. The second study, although a pilot study (number $[\mathrm{n}]=27$ ), included an Internet-based self-management Website system, called electronic outpatient cardiac rehabilitation (eOCR), through which cardiac case manager(s) could deliver education, track patient progress, and have contact with the patient and/or their caregiver via Web-based email and discussion boards, or by telephone. ${ }^{48} \mathrm{An}$ online workbook guided the patients week-by-week through their self-managed, individualized CR program, in which case managers monitored their progress weekly. The eOCR system was able to increase the reach of a CR and secondary prevention program within regions where previously limited services had been available. The validity of eOCR to demonstrate clinical improvements has yet to be reported.

Recently, researchers have taken advantage of Smartphone capabilities and features to develop and investigate novel models for home-based CR delivery. ${ }^{55}$ The features that have particularly attracted the use of the homecare delivery of CR include SMS-based interventions, journaling applications, built-in and connected measurement devices, and remote coaching.

Lounsbury et $\mathrm{al}^{49}$ examined the effect of a SMS textmessaging program on the number of sessions completed in outpatient $\mathrm{CR}$, together with other outcomes. Text messages sent 5-7 times per week consisted of heart-healthy tips, requests for weight, minutes of exercise, $\mathrm{BP}$, and medication adherence. The study demonstrated that patients who participated in the text-messaging program attended significantly more sessions and were more likely to complete outpatient CR than patients who did not.

An innovative text message and Internet-based delivery of CR (mHealth) was recently developed by Pfaeffli et al ${ }^{56}$ to improve adherence to lifestyle changes. Following a successful pilot study, ${ }^{56}$ which indicated the mHealth program to be an effective way to deliver exercise-based CR, an intervention was introduced (Text4Heart), which is currently being evaluated in a RCT. ${ }^{50}$ Participants receive a tailored program of SMS text messages via their mobile phone with evidencebased information on actions that will reduce the risk of subsequent events. The results from these research studies could aid in understanding the effectiveness of mobile phone applications, combined with health coaching, used in longterm interventions requiring a degree of self-management.

Walters et $\mathrm{al}^{57}$ designed and developed a Smartphone- and Internet-based homecare delivery model in alignment with an Australian (Queensland) state health service delivery of center-based CR, called the Care Assessment Platform (CAP). The CAP-CR model was the first to employ new-generation Smartphones with built-in sensors, mobile health diary applications, and a corresponding connected Internet portal to deliver components of a comprehensive CR program at home. ${ }^{57}$ The mobile applications included the processing of physical activity measurement from a built-in accelerometer and a journaling application (WellnessDiary [Nokia Research Centre, Media Technologies Lab, Tampere, Finland]), ${ }^{58}$ which supported logging a wide range of health-related states and activities. Home-based CR participants were able to view their own recorded data on a daily, weekly, or monthly basis, displayed as text and/or graphs on the Smartphone provided. The CAP-CR model also employed remote coaching by 
a dedicated mentor, specifically trained for the delivery of the program, to provide weekly scheduled telephone consultations with patients at home after reviewing the patients' updated data. ${ }^{57}$ The results of a RCT validating CAP-CR home-based $\mathrm{CR}$ delivery were published recently. ${ }^{51}$ The findings were remarkable in demonstrating not only improved uptake, but an adherence of $94 \%$ among CAP-CR participants, which resulted in completion rates of $>30 \%$ when compared to those attending center-based CR programs. ${ }^{51}$ Moreover, CAP-CR participants demonstrated similar improvements in physical activity, nutrition, and the lowering of depression as those of the center-based CR group. CAP-CR was also effective in significantly reducing anxiety and increasing HRQoL.

\section{Discussion}

In developed countries, CVD remains the first cause of death and disability. ${ }^{59}$ Over the last few decades, evidence has shown CR to be highly effective as a secondary prevention for patients recovering after a heart attack or heart surgery, and it is known to decrease the subsequent risk of total mortality, cardiovascular mortality, and cardiovascular morbidity. ${ }^{60,61}$ Despite the clear health benefits of CR programs, studies have shown that referral and participation rates of traditional center-based CR programs remain alarmingly low., ${ }^{9,29,62}$ To overcome some of the barriers to the traditional delivery of $\mathrm{CR}$, alternative delivery approaches have been developed over the last 20 years.

\section{Cardiac rehabilitation with telephone support}

In the 1990s, CR programs evolved to become nurse-managed, telephone-supported, home-based CR programs. The MULTIFIT was the pioneer of such programs ${ }^{36}$ and showed positive results in addressing the majority of CVD risk factors (physical capacity, lifestyle, and biomedical factors) at home. Subsequent comparable studies confirmed the potential of these programs to demonstrate further improvements in mental health outcomes and QoL. ${ }^{37,39}$ Another approach has been to include structured or scripted coaching sessions $\mathrm{s}^{38,40}$ and a self-help manual, ${ }^{34}$ which have also been effective in improving mental health outcomes and QoL. Although telephone-supported $\mathrm{CR}$ programs have been effective, there was still a constant need for clinical staff to have verbal communication with CR clients to monitor their progress. This was found not only to be labor intensive and expensive, ${ }^{40}$ but it sometimes narrowed telephone-supported home CR to low-intensity exercise programs due to the unsupervised nature of the delivery.

The introduction of the simultaneous transmission of ECG and voice during CR sessions has facilitated remote performance monitoring of ambulant rehabilitation without compromising the safety of exercise sessions. ${ }^{42,43}$ Access to telephones became standard to most households, which makes transtelephonic ECG monitoring a feasible technology solution for unmonitored or intermittently-monitored exercise sessions for home-based CR. However, while transtelephonic ECG monitoring may improve patient adherence to exercise and allow for home monitoring, it somewhat restricts the patient's lifestyle because it requires them to be equipped and confined to a specific location of the home to be monitored.

\section{Cardiac rehabilitation delivery via the Internet and mobile technologies}

Despite the increasing accessibility of the Internet to homes, take-up of Internet-based health interventions has been somewhat slow. Studies in homecare CR delivery have recently leveraged these. ${ }^{47,48}$ Although previous studies have reported Internet-based homecare CR delivery to be effective in improving compliance rates ${ }^{47,54,63}$ and physical activity ${ }^{64}$ many of these have been developmental and pilot studies. A previous RCT study by Southard et al ${ }^{65}$ used an Internet case management system to deliver home-based CR to clients through online chats to clinicians with online educational material. Although the Internet-based intervention showed a reduction in body weight, it did not significantly change the patients' exercise capacity or other risk factors (lipids, depression, or diet). Unlike the Southard et al study, a more recent RCT study by Lear et al, ${ }^{47}$ mentioned earlier, included a structured exercise program (via treadmill) for their innovative Web-based heart rate monitoring. While the results were positive in addressing accessibility to CR in remote geographic locations, as well as to health care and improvement in exercise capacity, changes in other key risk factors were limited, despite the provision of behavioral counseling. In the vCRP study, the level of engagement with the website varied noticeably. This supports previous studies where compliance to adhere to Internet-based CR interventions has been questionable. ${ }^{48,54}$ Hence, the design of Internet-based delivery CR warrants further improvement to afford CR participants the flexibility to adhere to their CR program, such as attending to exercises and monitoring health parameters. The advent of the provision of Internet services and accessibility through recent advances made in mobile phone handsets and tablets could make this flexibility possible.

Advances in mobile phones have become particularly attractive for the delivery of health interventions because of: 1) the widespread adoption of phones; 2) the fact that they form 
part of one's lifestyle as a communication tool for voice and text messaging; and, more recently, 3) smarter features with in-built sensors are available that enable geolocation (global positioning systems), activity measurement (accelerometers), storage, and connectivity to computer (Internet) applications via the mobile network (hence, termed the Smartphone). Recently, Smartphones, have employed wireless connectivity features to connect to health devices such as BP and glucose level monitors, thereby enabling the automated and accurate capture of measurements as they are performed.

With these capabilities offered by Smartphones, the technology is well placed to provide lifestyle flexibility for participants to monitor their exercise and other key cardiovascular risk factors. Through this, the CR participant could share monitored data of his or her progress from his or her Smartphone to a clinical portal, where guidance can be offered remotely by a care provider; it also enables the participant to self-manage in between clinical consultations. The advanced capabilities of Smartphones, as well as connectivity to remote Internet services, served as the impetus to design the homecare delivery model of the CAP by Walters et al, to deliver a comprehensive CR program remotely. ${ }^{57}$ That is, ensuring CR provision includes the monitoring of a participant's lifestyle and biomedical risk factor modifications through close guidance and counseling by care providers or coordinators, particularly to achieve individualized goals according to the participant's cardiac health profile. The RCT of this model was the first mobile phone delivery of homebased CR to be clinically validated, and to demonstrate its potential to overcome the service issue of low completion currently faced by the traditional delivery of CR. ${ }^{51}$

\section{Challenges and future perspectives}

While the clinical validation of innovative CR interventions are being researched to contribute toward proving improved health outcomes, effective implementation and adoption require translation into policy and action. Care systems have not accepted technology solutions as eagerly as might have been anticipated, and obstacles to uptake have been identified as a lack of reimbursement for physicians offering remote medical treatment, regulatory and professional liability concerns, and the accuracy of data. ${ }^{66}$ An important issue to consider in the development and implementation of effective technological interventions for home-based CR is that these interventions could be perceived as undermining important aspects of care, with some professionals fearing that new technology will replace them and take away direct human contact. ${ }^{67}$ Implementing a technology-supported CR program should comply with measures of technology acceptance, particularly in terms of ease of use, compatibility of programs with the patients' needs and practices, and relative advantages offered to the patient. ${ }^{68}$ This highlights the importance of users' perspectives when designing, implementing, and evaluating such interventions, and the need for programs to meet patient and clinician requirements. Changes in the existing $\mathrm{CR}$ services and systems may require new clinical responsibilities, time for training, and the development and openness to new ways of doing things. From a change management perspective, the clinicians' roles have to be defined and implemented to align with current practices without negatively impacting on existing staff and services in new care models.

As more evidence emerges about its efficacy and challenges (such as data management, privacy issues, and technology interoperability), and as reliability and governance are addressed, ICT has the potential to revolutionize the way in which CR programs are delivered, as well as to address some of the barriers faced by center-based programs. Instead of providing one uniform intervention for all, irrespective of the patient's condition, it is appropriate to provide a set of choices of interventions or components thereof from which individuals can then self-tailor an intervention that best suits their personal needs and circumstances.

\section{Acknowledgment}

The authors would like to thank both Professors Kerry Mummery and Robyn Clark for the screen shots of the eOCR portal in Figure 3A.

\section{Disclosure}

The authors report no conflicts of interest in this work.

\section{References}

1. Aboderin I, Kalache A, Ben-Shlomo Y, et al. Life Course Perspectives on Coronary Heart Disease, Stroke and Diabetes: Key Issues and Implications for Policy and Research. Geneva, Switzerland: World Health Organization; 2002.

2. Balady GJ, Williams MA, Ades PA, et al; American Heart Association Exercise, Cardiac Rehabilitation, and Prevention Committee, the Council on Clinical Cardiology; American Heart Association Council on Cardiovascular Nursing; American Heart Association Council on Epidemiology and Prevention; American Heart Association Council on Nutrition, Physical Activity, and Metabolism; American Association of Cardiovascular and Pulmonary Rehabilitation. Core components of cardiac rehabilitation/secondary prevention programs: 2007 update: a scientific statement from the American Heart Association Exercise, Cardiac Rehabilitation, and Prevention Committee, the Council on Clinical Cardiology; the Councils on Cardiovascular Nursing, Epidemiology and Prevention, and Nutrition, Physical Activity, and Metabolism; and the American Association of Cardiovascular and Pulmonary Rehabilitation. Circulation. 2007;115(20):2675-2682.

3. Lavie CJ, Milani RV. Cardiac rehabilitation and exercise training in secondary coronary heart disease prevention. Prog Cardiovasc Dis. 2011;53(6):397-403 
4. Papadakis S, Oldridge NB, Coyle D, et al. Economic evaluation of cardiac rehabilitation: a systematic review. Eur J Cardiovasc Prev Rehabil. 2005;12(6):513-520.

5. Wenger NK. Current status of cardiac rehabilitation. JAm Coll Cardiol. 2008;51(17):1619-1631.

6. Bethell H, Lewin R, Evans J, Turner S, Allender S, Petersen S. Outpatient cardiac rehabilitation attendance in England: variability by region and clinical characteristics. J Cardiopulm Rehabil Prev. 2008;28(6):386-391.

7. Brown TM, Hernandez AF, Bittner V, et al; American Heart Association Get With The Guidelines Investigators. Predictors of cardiac rehabilitation referral in coronary artery disease patients: findings from the American Heart Association's Get With The Guidelines Program. J Am Coll Cardiol. 2009;54(6):515-521.

8. National Heart Foundation of Australia \& Australian Cardiac Rehabilitation Association. Recommended Framework for Cardiac Rehabilitation'04. Canberra: National Heart Foundation of Australia; 2004.

9. Suaya JA, Shepard DS, Normand SL, Ades PA, Prottas J, Stason WB. Use of cardiac rehabilitation by Medicare beneficiaries after myocardial infarction or coronary bypass surgery. Circulation. 2007;116(15): 1653-1662.

10. Thomas RJ. Cardiac rehabilitation/secondary prevention programs: a raft for the rapids: why have we missed the boat? Circulation. 2007; 116(15):1644-1646.

11. Fernandez RS, Salamonson Y, Griffiths R, Juergens C, Davidson P. Sociodemographic predictors and reasons for participation in an outpatient cardiac rehabilitation programme following percutaneous coronary intervention. Int J Nurs Pract. 2008;14(3):237-242.

12. Johnson NA, Inder KJ, Ewald BD, James EL, Bowe SJ. Association between participation in outpatient cardiac rehabilitation and selfreported receipt of lifestyle advice from a healthcare provider: results of a population-based cross-sectional study. Rehabil Res Pract. 2010;2010: 541741.

13. Nagle A, Wiggers J, Fisher J, Johnson N, Inder K. Prevalence and predictors of being invited, attending and completing phase II outpatient cardiac rehabilitation. Heart Lung Circ. 2000;9(3):A167.

14. Scott IA, Lindsay KA, Harden HE. Utilisation of outpatient cardiac rehabilitation in Queensland. Med J Aust. 2003;179(7):341-345.

15. Shepherd F, Battye K, Chalmers E. Improving access to cardiac rehabilitation for remote Indigenous clients. Aust N Z J Public Health. 2003;27(6):632-636.

16. British Heart Foundation. National Audit of Cardiac Rehabilitation (NACR). 2011. Available from: http://www.cardiacrehabilitation.org. uk/docs/2011.pdf. Accessed February 12, 2015.

17. Dunlay SM, Witt BJ, Allison TG, et al. Barriers to participation in cardiac rehabilitation. Am Heart J. 2009;158(5):852-859.

18. Goel K, Lennon RJ, Tilbury RT, Squires RW, Thomas RJ. Impact of cardiac rehabilitation on mortality and cardiovascular events after percutaneous coronary intervention in the community. Circulation. 2011;123(21):2344-2352.

19. Witt BJ, Jacobsen SJ, Weston SA, et al. Cardiac rehabilitation after myocardial infarction in the community. J Am Coll Cardiol. 2004;44(5): 988-996.

20. Alter DA, Habot J, Grace SL, et al. Ambulatory surveillance of patients referred for cardiac rehabilitation following cardiac hospitalization: a feasibility study. Can J Cardiol. 2012;28(4):497-501.

21. Martin BJ, Hauer T, Arena R, et al. Cardiac rehabilitation attendance and outcomes in coronary artery disease patients. Circulation. 2012;126(6): $677-687$.

22. van Engen-Verheul M, de Vries H, Kemps H, Kraaijenhagen R, de Keizer N, Peek N. Cardiac rehabilitation uptake and its determinants in the Netherlands. Eur J Prev Cardiol. 2013;20(2): 349-356.

23. Ghisi GL, Polyzotis P, Oh P, Pakosh M, Grace SL. Physician factors affecting cardiac rehabilitation referral and patient enrollment: a systematic review. Clin Cardiol. 2013;36(6):323-335.
24. Evenson KR, Fleury J. Barriers to outpatient cardiac rehabilitation participation and adherence. J Cardiopulm Rehabil. 2000;20(4): 241-246.

25. Gordon NF, Salmon RD, Mitchell BS, et al. Innovative approaches to comprehensive cardiovascular disease risk reduction in clinical and community-based settings. Curr Atheroscler Rep. 2001;3(6):498-506.

26. Grace SL, Tan Y, Simpson C, Chessex C. Perceptions of cardiac specialists and rehabilitation programs regarding patient access to cardiac rehabilitation and referral strategies. J Cardiopulm Rehabil Prev. 2012;32(3): 135-140.

27. Grace SL, Grewal K, Stewart DE. Factors affecting cardiac rehabilitation referral by physician specialty. $J$ Cardiopulm Rehabil Prev. 2008;28(4):248-252.

28. Gurewich D, Prottas J, Bhalotra S, Suaya JA, Shepard DS. System-level factors and use of cardiac rehabilitation. J Cardiopulm Rehabil Prev. 2008;28(6):380-385.

29. Neubeck L, Freedman SB, Clark AM, Briffa T, Bauman A, Redfern J. Participating in cardiac rehabilitation: a systematic review and meta-synthesis of qualitative data. Eur J Prev Cardiol. 2012;19(3): 494-503.

30. Jones LW, Farrell JM, Jamieson J, Dorsch KD. Factors influencing enrollment in a cardiac rehabilitation exercise program. Can $J$ Cardiovasc Nurs. 2003;13(1):11-15.

31. Cooper AF, Jackson G, Weinman J, Horne R. A qualitative study investigating patients' beliefs about cardiac rehabilitation. Clin Rehabil. 2005;19(1):87-96.

32. Kotseva K, Wood D, De Backer G, De Bacquer D; EUROASPIRE III Study Group. Use and effects of cardiac rehabilitation in patients with coronary heart disease: results from the EUROASPIRE III survey. Eur J Prev Cardiol. 2013;20(5):817-826.

33. Taylor RS, Dalal H, Jolly K, Moxham T, Zawada A. Home-based versus centre-based cardiac rehabilitation. Cochrane Database Syst Rev. 2010;(1):CD007130.

34. Dalal HM, Evans PH, Campbell JL, et al. Home-based versus hospitalbased rehabilitation after myocardial infarction: A randomized trial with preference arms - Cornwall Heart Attack Rehabilitation Management Study (CHARMS). Int J Cardiol. 2007;119(2):202-211.

35. Clark RA, Conway A, Poulsen V, Keech W, Tirimacco R, Tideman P. Alternative models of cardiac rehabilitation: A systematic review. Eur J Prev Cardiol. 2015;22(1):35-74.

36. DeBusk RF. MULTIFIT: a new approach to risk factor modification. Cardiol Clin. 1996;14(1):143-157.

37. Kodis J, Smith KM, Arthur HM, Daniels C, Suskin N, McKelvie RS. Changes in exercise capacity and lipids after clinic versus home-based aerobic training in coronary artery bypass graft surgery patients. J Cardiopulm Rehabil. 2001;21(1):31-36.

38. Vale MJ, Jelinek MV, Best JD, et al; COACH Study Group. Coaching patients On Achieving Cardiovascular Health $(\mathrm{COACH})$ : a multicenter randomized trial in patients with coronary heart disease. Arch Intern Med. 2003;163(22):2775-2783.

39. Arthur HM, Smith KM, Kodis J, McKelvie R. A controlled trial of hospital versus home-based exercise in cardiac patients. Med Sci Sports Exerc. 2002;34(10):1544-1550.

40. Hawkes AL, Patrao TA, Atherton J, et al. Effect of a telephone-delivered coronary heart disease secondary prevention program (proactive heart) on quality of life and health behaviours: primary outcomes of a randomised controlled trial. Int J Behav Med. 2013;20(3): 413-424.

41. Hawkes AL, Atherton J, Taylor CB, et al. Randomised controlled trial of a secondary prevention program for myocardial infarction patients ('ProActive Heart'): study protocol. Secondary prevention program for myocardial infarction patients. BMC Cardiovasc Disord. 2009; 9:16.

42. Ades PA, Pashkow FJ, Fletcher G, Pina IL, Zohman LR, Nestor JR. A controlled trial of cardiac rehabilitation in the home setting using electrocardiographic and voice transtelephonic monitoring. Am Heart J. 2000;139(3):543-548. 
43. Körtke H, Stromeyer H, Zittermann A, et al. New East-Westfalian Postoperative Therapy Concept: a telemedicine guide for the study of ambulatory rehabilitation of patients after cardiac surgery. Telemed $J$ E Health. 2006;12(4):475-483.

44. Vale MJ, Jelinek MV, Best JD, Santamaria JD. Coaching patients with coronary heart disease to achieve the target cholesterol: a method to bridge the gap between evidence-based medicine and the "real world" - randomized controlled trial. J Clin Epidemiol. 2002;55(3): 245-252.

45. O’Neil A, Hawkes AL, Atherton JJ, et al. Telephone-delivered health coaching improves anxiety outcomes after myocardial infarction: the 'ProActive Heart' trial. Eur J Prev Cardiol. 2014;21(1): 30-38.

46. Turkstra E, Hawkes AL, Oldenburg B, Scuffham PA. Cost-effectiveness of a coronary heart disease secondary prevention program in patients with myocardial infarction: results from a randomised controlled trial (ProActive Heart). BMC Cardiovasc Disord. 2013; $13: 33$.

47. Lear SA, Singer J, Banner-Lukaris D, et al. Randomized trial of a virtual cardiac rehabilitation program delivered at a distance via the Internet. Circ Cardiovasc Qual Outcomes. 2014;7(6):952-959.

48. Clark RA, Tideman P, Tirimacco R, et al. A pilot study of the feasibility of an Internet-based electronic Outpatient Cardiac Rehabilitation (eOCR) program in rural primary care. Heart Lung Circ. 2013;22(5): 352-359.

49. Lounsbury P, Gordon E, Clarke W, Elokda AS. Text-messaging program improves outcomes in outpatient cardiovascular rehabilitation. AACVPR Annual Meeting. 2013. Available from: http://www.aacvpr.org/Portals/0/ events_edu/annuallmeeting13/28AMSyllabus/Text\%20Messaging\%20 Program\%20-\%20Lounsbury.pdf. Accessed February 12, 2015.

50. Dale LP, Whittaker R, Jiang Y, Stewart R, Rolleston A, Maddison R. Improving coronary heart disease self-management using mobile technologies (Text4Heart): a randomised controlled trial protocol. Trials. 2014;15:71.

51. Varnfield M, Karunanithi M, Lee CK, et al. Smartphone-based home care model improved use of cardiac rehabilitation in postmyocardial infarction patients: results from a randomised controlled trial. Heart. 2014;100(22):1770-1779.

52. Kotb A, Hsieh S, Wells GA. The effect of telephone support interventions on coronary artery disease (CAD) patient outcomes during cardiac rehabilitation: a systematic review and meta-analysis. PLoS One. 2014;9(5):e96581.

53. Piette JD. Using Telephone Support to Manage Chronic Disease. Oakland, CA: California HealthCare Foundation; 2005.

54. Munro J, Angus N, Leslie SJ. Patient focused Internet-based approaches to cardiovascular rehabilitation - a systematic review. J Telemed Telecare. 2013;19(6):347-353.
55. Beatty AL, Fukuoka Y, Whooley MA. Using mobile technology for cardiac rehabilitation: a review and framework for development and evaluation. J Am Heart Assoc. 2013;2(6):e000568.

56. Pfaeffli L, Maddison R, Whittaker R, et al. A mHealth cardiac rehabilitation exercise intervention: findings from content development studies. BMC Cardiovasc Disord. 2012;12:36.

57. Walters DL, Sarela A, Fairfull A, et al. A mobile phone-based care model for outpatient cardiac rehabilitation: the care assessment platform (CAP). BMC Cardiovasc Disord. 2010;10:5.

58. Mattila E, Pärkkä, Hermersdorf M, et al. Mobile diary for wellness management - results on usage and usability in two user studies. IEEE Trans Inf Technol Biomed. 2008;12(4):501-512.

59. World Health Organization; World Heart Federation; World Stroke Organization, editors. Global Atlas on Cardiovascular Disease Prevention and Control: Policies, Strategies and Interventions. Geneva, Switzerland: World Health Organization; 2011.

60. Clark AM, Hartling L, Vandermeer B, McAlister FA. Meta-analysis: secondary prevention programs for patients with coronary artery disease. Ann Intern Med. 2005;143(9):659-672.

61. Taylor RS, Brown A, Ebrahim S, et al. Exercise-based rehabilitation for patients with coronary heart disease: systematic review and metaanalysis of randomized controlled trials. Am J Med. 2004;116(10): 682-692.

62. Jolly K, Taylor RS, Lip GY, Stevens A. Home-based cardiac rehabilitation compared with centre-based rehabilitation and usual care: a systematic review and meta-analysis. Int J Cardiol. 2006;111(3):343-351.

63. Dew MA, Goycoolea JM, Harris RC, et al. An internet-based intervention to improve psychosocial outcomes in heart transplant recipients and family caregivers: development and evaluation. J Heart Lung Transplant. 2004;23(6):745-758.

64. Reid RD, Morrin LI, Beaton LJ, et al. Randomized trial of an internetbased computer-tailored expert system for physical activity in patients with heart disease. Eur J Prev Cardiol. 2012;19(6):1357-1364.

65. Southard BH, Southard DR, Nuckolls J. Clinical trial of an Internetbased case management system for secondary prevention of heart disease. J Cardiopulm Rehabil. 2003;23(5):341-348.

66. Fisher L, Dickinson WP. New technologies to advance self-management support in diabetes: not just a bunch of cool apps! Diabetes Care. 2011;34(1):240-243.

67. Magnusson L, Hanson E. Supporting frail older people and their family carers at home using information and communication technology: cost analysis. J Adv Nurs. 2005;51(6):645-657.

68. Oldenburg B, Glanz K. Diffusion of innovations. In: Glanz K, Rimer BK, Viswanath K, editors. Health Behavior and Health Education: Theory, Research, and Practice. 4th ed. San Francisco, CA: John Wiley and Sons; 2008.
Smart Homecare Technology and TeleHealth

\section{Publish your work in this journal}

Smart Homecare Technology and TeleHealth is an international, peer-reviewed, open access online journal publishing original research, reviews, editorials and commentaries on the application of technology to support people and patients at home and in assisted living centers to optimize healthcare and management resources. Specific topics in the journal include: Development and application of

\section{Dovepress}

devices within the home and embedded in appliances; Healthcare provider communication and education tools; and drug ordering and adherence. The manuscript management system is completely online and includes a very quick and fair peer-review system, which is all easy to use. Visit http://www.dovepress.com/ testimonials.php to read real quotes from published authors. 